\title{
MULTIDIMENSIONALIDADE DO DIREITO À CIDADE NO ESTATUTO DA CIDADE
}

\author{
Jussara Romero Sanches ${ }^{1}$ \\ Miguel Etinger de Araujo Junior ${ }^{2}$
}

\section{RESUMO:}

Viver no ambiente urbano é uma realidade para mais de $50 \%$ da população mundial. No contexto do desenvolvimento e planejamento urbano o objetivo deste estudo é compreender de que modo a multidimensionalidade do direito à cidade está presente na legislação brasileira. Por meio do método indutivo e revisão bibliográfica a respeito da temática, percebe-se que o direito à cidade não é unívoco. O Direito à Cidade conjuga em si uma série outras dimensões. O Estatuto da Cidade, alcança, em certa medida, a multidimensionalidade do Direito à Cidade.

Palavras-chave: Cidades sustentáveis; Planejamento urbano; Direito à Cidade; Estatuto da Cidade; Multidimensionalidade.

\section{MULTIDIMENSIONALITY OF THE RIGHT TO THE CITY IN THE CITY STATUTE}

\begin{abstract}
:
Living in the urban environment is a reality for more than $50 \%$ of the world's population. In the context of development and urban planning the objective of this study is to understand how the multidimensionality of the right to the city is present in the Brazilian legislation. By means of the inductive method and bibliographical revision on the subject, it is perceived that the right to the city is not a unequivocal. The Right to the City combines in itself a series of other dimensions. The Statute of the City reaches, the multidimensionality of the Right to the City.
\end{abstract}

Keywords: Sustainable Cities; Urban Planning; Right to the City; City Statute. Multidimensionality.

\section{INTRODUÇÃO}

O desenvolvimento urbano contemporâneo tem como base, no âmbito internacional, bem como no âmbito interno, o Direito à Cidade. Porém, este direito não apresenta uma definição unívoca, e sua conceituação está em constante transformação. É neste contexto que o presente trabalho tem como objetivo levantar a reflexão sobre os

\footnotetext{
${ }^{1}$ Mestranda do programa de Mestrado em Direito Negocial da Universidade Estadual de Londrina. Bolsista CAPES. Especialista em Direito do Estado pela mesma instituição e em Gestão, Licenciamento e Auditoria Ambiental pela Universidade do Norte do Paraná. Graduada em Direito e em Ciências Sociais.

${ }^{2}$ Doutor em Direito da Cidade pela Universidade do Estado do Rio de Janeiro. Mestre em Direito pela Universidade Estácio de Sá - RJ. Professor adjunto da Universidade Estadual de Londrina na graduação e pós-graduação.
} 
contornos que o Direito à Cidade possui, para compreender sua complexidade e sua multidimensionalidade.

Amparado no método indutivo, e utilizando levantamento bibliográfico e análise de legislação, buscou-se compreender os contornos do Direito à Cidade nas suas múltiplas dimensões. A primeira parte deste estudo se dedica a reflexão sobre a origem do conceito de Direito à Cidade, tendo como base o livro de Henri Lefebvre, que leva o mesmo nome. Mas também recorreu-se a autores contemporâneos que também discutem a temática, sem, no entanto, desconfigurar os elementos da elaboração inicial.

A segunda parte deste estudo se volta à compreensão de como o Direito à Cidade se desenvolveu no cenário internacional. Busca-se apontar a forma como a discussão sobre as questões urbanas foram propostas inicialmente vinculadas à discussão sobre sustentabilidade.

Neste sentido, demonstra-se nesta segunda seção como a questão urbana passou da sustentabilidade para constituir-se enquanto uma questão de Direito à Cidade. Apresenta-se portanto, algumas definições de Direito à Cidade contidas tanto na Carta Mundial pelo Direito à Cidade, quanto na Nova Agenda Urbana, documento elaborado no âmbito da Conferência das nações Unidas sobre Moradia e Desenvolvimento Urbano Sustentável, realizada no Equador em 2016.

Na última seção, a discussão volta-se à realidade brasileira, com o intuito de apontar algumas reflexões acerca do processo de urbanização, bem como de algumas características que o particularizam. A partir dessa contextualização, discute-se o processo de incorporação na legislação brasileira na temática da sustentabilidade urbana.

Tendo como ponto de partida a Constituição Federal de 1988, com um capítulo inédito a respeito da política urbana, e avançando até a promulgação da Lei no 10.257 de 2001, autodenominada Estatuto da Cidade, na qual há previsão expressa do direito à cidades sustentáveis. Através dessa análise, busca-se compreender de que forma a multidimensionalidade que compreende o Direito à Cidade pode aparecer na legislação brasileira, em especial no que tange às diretrizes gerais que norteiam a política urbana brasileira, com objetivo de desenvolver as funções sociais da cidade e da propriedade urbana. 


\section{DIREITO À CIDADE}

O termo Direito à Cidade consagra-se no debate sobre a construção do espaço urbano, através do livro homônimo, O Direito à Cidade, escrito pelo filósofo e sociólogo Henri Lefebvre, em 1968. Marcado sensivelmente pela tradição marxista, o livro de Henri Lefebvre se configura como profundo questionamento sobre a forma como as cidades estão se desenvolvendo nas sociedades capitalistas.

Apesar do livro poder ser localizado geográfica e historicamente, nas transformações pelas quais a cidade de Paris estava passando na década de 1960 (HARVEY, 2014, p. 10), o livro contribui de forma significativa para a construção das bases filosóficas do conceito de direito à cidade. Se configura, como o próprio autor afirma, como um instrumento de rompimento com a forma com a qual as cidades estão sendo construídas, não para dar um modelo novo, mas para abrir o caminho para novas possibilidades e novos horizontes (LEFEBVRE, 2001, p. 9).

A cidade antiga, aquela que não foi transformada pelos processos de industrialização e urbanização intensos a era moderna, configurava para Henri Lefebvre (2001, p. 23) o lugar do habitar, que "era participar de uma vida social, de uma comunidade, aldeia ou cidade. A vida urbana detinha, entre outras, essa qualidade, esse atributo. Ela deixa habitar, permitia que citadinos-cidadãos habitassem". A cidade destaca-se enquanto lócus de trocas sociais, de convício social.

No entanto, esse espaço do convívio social se perde ao longo das transformações que pelas quais as cidades passam, na consolidação do sistema capitalista, é na cidade que "a oposição entre valor de uso (a cidade e a vida urbana, o tempo urbano) e o valor de troca (os espaços comprados e vendidos, o consumo de produtos, dos bens, dos lugares e dos signos) surgirá em plena luz" (LEFEBVRE, 2001, p.35).

O direito à cidade para Henri Lefebvre surge na superação de uma urbanidade na qual o valor de troca prevalece. Neste sentido, analisando o cenário contemporâneo, Letícia

Marques Osório (2006, p. 195) assevera que o Direito à Cidade "busca reverter a predominância dos valores econômicos sobre as funções sociais da cidade", promovendo de acordo com a autora, que a cidade seja o espaço do usufruto coletivo da 
riqueza, da cultura, dos bens, bem como do conhecimento, no qual não prevaleça uma proteção que discrimina alguns grupos despossuídos de bens, propriedades e capital.

Para Henri Lefebvre, este direito não se constitui como a reconstrução de uma cidade antiga, mas configura-se como a construção de uma nova cidade, em outra escala, tendo como base outras condições. É que se percebe nas palavras de Henri Lefebvre (2001, p. 139):

O direito à cidade (não à cidade arcaica mas à vida urbana, à centralidade renovada, aos locais de encontro e de trocas, aos ritmos e vida e empregos do tempo que permitem o uso pleno e inteiro desses momentos e locais etc.). A proclamação e a realização da vida urbana como reino do uso (da troca e do encontro separados do valor de troca) exigem o domínio do econômico (do valor de troca, do mercado e da mercadoria) e por conseguinte se inscrevem nas perspectivas da revolução sob a hegemonia da classe operária.

Sem abandonar o caráter revolucionário com o qual o Direito à cidade foi desenvolvido na obra de Henri Lefebvre, David Harvey (2013, p. 63) também questiona a forma capitalista de construção do espaço urbano, da sua mercantilização e da concentração do poder de transformação desse espaço nas mãos de poucos. É o que se compreende das palavras do autor quando afirma que:

O direito à cidade como hoje existe, como se constitui atualmente, encontrasse muito mais estreitamente confinado, na maior parte do casos, nas mãos de uma pequena elite política e econômica com condições de moldar a cidade cada vez mais segundo suas necessidades particulares e seus mais profundos desejos.

Neste sentido, David Harvey (2013, p. 30) afirma que "reivindicar o direito à cidade no sentido que aqui proponho equivale a reivindicar algum tipo de poder configurador sobre os processos de urbanização, sobre o modo como nossas cidades são feitas e refeitas, e pressupõe fazê-lo de maneira radical e fundamental". O direito à cidade é o direito de transformar a cidade de acordo com as necessidades de todos e não de alguns grupos específicos.

Na mesma esteira de Henri Lefebvre, David Harvey (2013, p. 33) afirma que o direito à cidade não é o direito ao retorno ao que já existiu, mas o direito transformado e renovado à vida urbana, "o direito à cidade, como comecei a dizer, não é apenas um direito condicional de acesso àquilo que já existe, mas sim um direito ativo de fazer a cidade diferente, de formá-la mais de acordo com nossas necessidades coletivas (por 
assim dizer), definir uma maneira alternativa de simplesmente ser humano". Para o autor, se a forma como o muno urbano existe hoje foi fruto e resultados das relações sociais, ele pode ser refeito e transformado a partir das mesmas relações.

Analisando o Direito à Cidade desenvolvido por Henri Lefebvre, Edésio Fernandes (2007, p. 208) afirma que:

O conceito de "direito à cidade" de Henri Lefebvre foi muito mais uma plataforma político-filosófica e não explorava diretamente como, ou em que medida, a ordem legal determinava o padrão excludente de desenvolvimento urbano.

O autor destaca que a contribuição que a obra de Henri Lefebvre deixa no cenário de discussões sobre o direito à cidade, é a compreensão dos aspectos socioeconômicos, políticos, ideológicos e culturais do processo de urbanização (FERNANDES, 2007, p. 208). No entanto, como autor aponta, a obra não se propôs a explorar o aspecto jurídico do direito à cidade, ficando a cargo de outros pensadores a articulação da proposta de Henri Lefebvre sobre o direito à Cidade com o mundo jurídico.

A inserção do direito à cidade nos ordenamentos jurídicos nacionais, tanto brasileiro, como de outros países, é antecedido pela consolidação do direito à cidade no cenário internacional. Dessa forma, a seção seguinte se voltará à análise de como a temática urbana surge e se consolida nas discussões em âmbito internacional para que seção seguinte seja abordada a forma como o direito à cidade se constitui na legislação brasileira.

\section{O MEIO AMBIENTE URBANO NO DEBATE INTERNACIONAL}

A temática urbana e a discussão sobre como o ser humano estava construindo o espaço urbano, surge no cenário internacional em paralelo ao desenvolvimento do conceito de direito ambiental na década de 1970, de acordo José Antônio Tietzmann e Silva (2006, p. 138) no "momento em que o ser humano teve consciência da nocividade de suas ações para o meio natural, e, como consequência, para si mesmo”.

Neste contexto, o urbano começou a ser pensando nos moldes da sustentabilidade, apesar de acontecer em 1976 a Conferência de Vancouver que ficou conhecida como Conferência Habitat I, somente na década de 1990 é que de fato, o 
conceito de cidade sustentável se consolidou no quadro mundial (TIETZMANN E SILVA, 2006, 139).

A associação entre a noção de sustentabilidade e a questão urbana, de acordo com Henri Acserald (2001, p. 36) se origina "nas rearticulações políticas pelas quais um certo número de atores envolvidos na produção do espaço urbano procuram dar legitimidade às suas perspectivas, evidenciando a compatibilidade das mesmas com os propósitos de dar durabilidade ao desenvolvimento".

A definição do que seja uma cidade sustentável, não é tarefa simples. José Antônio Tietzmann e Silva (2006, p. 135) afirma que apesar de ser simples e bela a explicação do que vem a ser uma cidade sustentável, ela "representa um conceito verdadeiramente difícil de se concretizar [...] devem ser levado em consideração os fatores ambientais, sociais, culturais e econômicos, por exemplo, encontrados nos processo de tomada de decisão do Poder Público".

Mas a partir de vários estudos, José Antônio Tietzmann e Silva (2006, p. 137) aponta que a "a cidade tida como sustentável é aquela onde inexistem problemas, é uma cidade gerenciada pelo Poder Público, mas que conta com uma sociedade engajada e um setor privado atendo aos interesses coletivos". Tendo em vista a síntese apresentada, compreende-se o desafio de efetivação do conceito de cidade sustentável.

$\mathrm{Na}$ busca de efetivação de algum conceito de cidade justa, ou cidade sustentável, ocorre em1996 em Istambul, a Cúpula das Cidades, também conhecida como Habitat II, da qual resultou a Declaração de Istambul sobre estabelecimentos Humanos e a Agenda Habitat.

De acordo com Nelson Saule Júnior (1999, p. 325), citando a Ficha 1 da Agenda Habitat, esta "estabelece um conjunto de princípios, metas, compromissos e um plano global de ação, visando orientar, nas duas primeiras décadas do próximo século, os esforços nacionais e internacionais no campo da melhoria dos assentamentos humanos".

Neste contexto de encontros e textos internacionais que possuem como núcleo questões urbanas, é possível citar a Carta Mundial do Direito à Cidade. De acordo com a própria carta, reproduzida na integra por Orlando Alves dos Santos Júnior e Cristiano Müller (2008, p. 30) a elaboração da carta começou no I Fórum Social Mundial em 
Porto Alegre e contou coma participação de diversas camadas da sociedade, entre movimentos sociais populares, organizações não governamentais, sociedade civil organizada, "comprometidas com as lutas sociais por cidades mais justas, democráticas, humanas e sustentáveis". A carta tem como objetivo, difundir o reconhecimento no sistema internacional os direitos humanos do direito à cidade.

De acordo com o art. 1 da Carta Mundial pelo Direito à Cidade, reproduzida por Orlando Alves dos Santos Júnior e Cristiano Müller (2008, p. 31), o Direito à Cidade é definido:

Como o usufruto equitativo das cidades dentro dos princípios de sustentabilidade, democracia e justiça social; é um direito que confere legitimidade à ação e organização, baseado em seus usos e costumes, com o objetivo de alcançar o pleno exercício de direito a um padrão de vida adequado. O Direito à Cidade é interdependente a todos os direitos humanos internacionalmente reconhecidos, concebidos integralmente e inclui os direitos civis, políticos, econômicos, sociais, culturais e ambientais. Inclui também o direito à liberdade de reunião e organização, o respeito às minorias e à pluralidade étnica, racial, sexual e cultural; o respeito aos imigrantes e a garantia da preservação e herança histórica e cultural.

A definição de Direito à Cidade trazida pela carta deixa claro que o conceito é compreendido a partir da sua complexidade, uma vez que compreende diversos aspectos da vida e da vida urbana. Compreendido como essencial ao contemporâneo de bate sobre o desenvolvimento e planejamento urbano, o Direito à Cidade ganha espaço e passa a configurar como o núcleo da Nova Agenda Urbana, resultado da Conferência das Nações Unidas sobre Moradia e Desenvolvimento Urbano Sustentável, denominada de Habitat III, que ocorreu no Equador em 2016.

A Nova Agenda Urbana (2016) define um ideal de cidade para todos, que se refere:

A la igualdad en el uso y el disfrute de las ciudades y los asentamientos humanos, y buscando promover la integración y garantizar que todos los habitantes, tanto de las generaciones presentes como futuras, sin discriminación de ningún tipo, puedan crear ciudades y asentamientos humanos justos, seguros, sanos, accesibles, asequibles, resilientes y sostenibles, y habitar en ellos, a fin de promover la prosperidad y la calidad de vida para todos. ${ }^{3}$

\footnotetext{
${ }^{3} \mathrm{~A}$ igualdade no uso e no desfrute das cidades e dos assentamentos humanos, e buscando promover a integração e garantia de que todos os habitantes, tanto das gerações presentes como futuras, sem discriminação de nenhum tipo, possam criar cidades e assentamentos humanos justos, seguros, sãos, acessíveis, resilientes e sustentáveis, e habitá-los, a fim de promover a prosperidade e a qualidade de vida para todos. (tradução livre).
} 
Conjunto de medidas que, de acordo com a carta, são adotas pelos países através de leis, declarações, políticas e cartas, sob a denominação de Direito à Cidade. A Carta ainda complementa a ideia de Direito à Cidade afirmando que as cidades e assentamentos humanos, devem: cumprir sua função social, promovendo acesso à moradia digna e adequada, acesso ao saneamento, aos bens públicos, à segurança alimentar, à saúde, à educação, à infraestrutura, à mobilidade, ao transporte, à energia, à qualidade de ar e aos meios de vida.

Estimular a participação, a colaboração cívica que desenvolvam sentimentos de pertencimentos e de propriedade em seus habitantes; que promovam a igualdade de gênero e o empoderamento das mulheres e das meninas, através da promoção da igualdade de participação das mulheres em todas as esferas de decisões importantes, garantindo trabalho decente e de igual valor; promovam o crescimento, mas com sustentabilidade e inclusão, através do aproveitamento de economias locais; que se configurem como centros impulsionadores do desenvolvimento urbano, equilibrado, sustentável e integrado.

Devem ainda preocupar-se com a mobilidade urbana sustentável, acessível e segura para todos, tendo como base a idade e o gênero; promovam a elaboração de políticas públicas de redução e gestão contra riscos de desastres, que reduzam a vulnerabilidade e aumentem a capacidade de respostas diante dos perigos naturais, bem como promovam a diminuição e a adaptação à mudança climática, por fim e não menos importante, se preocupem com a proteção, a conservação, restauração de seus ecossistemas, recursos hídricos, habitat naturais e diversidade biológica.

Novamente destaca-se a complexidade associada ao Direito à Cidade, que não se compreende como mero acesso ao espaço urbano, mas conjuga em si a moradia digna, propriedade urbana, acesso à serviços e à infraestrutura pública, à participação de todos nos processos de planejamento e desenvolvimento urbano para que este seja direcionado a satisfação das necessidades coletivas.

\section{DIREITO À CIDADE NA LEGISLAÇÃO BRASILEIRA E SUA MULTIDIMENSIONALIDADE}


No ordenamento jurídico brasileiro é possível identificar, desde o texto constitucional, uma importante preocupação com o desenvolvimento urbano e a forma como este desenvolvimento deve ser ordenado. No entanto, essa preocupação, traduzida em textos legais 1988, representa uma luta engendrada no processo de urbanização do país, consolidado principalmente a partir da metade do século XX, e marcado sensivelmente pela desordem e pela ilegalidade.

Essa situação se explicita nas palavras de Edésio Fernandes (2010, p. 56) quando o autor aponta que "a rápida urbanização gerou e continua gerando uma profunda crise urbana caracterizada pela combinação de segregação socioespacial, déficit habitacional, impactos ambientais e acesso informal à terra urbana e à moradia". $\mathrm{Na}$ tentativa de explicar e compreender as causa de um processo de urbanização marcado pela informalidade, Ermínia Maricato (2013, p. 23) afirma que a tragédia urbana brasileira, não é resultado apenas das políticas econômicas adotadas ao longo nas décadas recentes, mas que "tem suas raízes muito firmes em cinco séculos de formação da sociedade brasileira, em especial da privatização da terra (1850) e da emergência do trabalho livre (1888)". Para a autora, uma das origens mais marcantes da expressiva ocupação do solo urbano de maneira informal, foi o processo de industrialização baseado em baixos salários.

Dessa forma, ao lado dos trabalhadores que não possuíam emprego, estavam aqueles que mesmo empregados, não recebiam soldos suficientes, capazes de arcar com as suas necessidades básicas de reprodução, muito menos com os custos da moradia. Neste sentido, Ermínia Maricato (2013, p. 41) afirma que "a cidade ilegal e precária é um subproduto dessa complexidade verificada no mercado de trabalho e da forma como se processou a industrialização". Renda e acesso ao solo urbano estão intimamente ligados, como afirma

Paul Singer (1979, p. 33) "a propriedade privada do solo urbano faz com que a posse de uma renda monetária seja requisito indispensável à ocupação do espaço urbano".

Na medida em que os rendimentos dos trabalhadores não eram suficientes para assegurar seu acesso ao solo urbano, cresceram significativamente as ocupação informais do espaço urbano, traço que marcou a urbanização brasileira. Outro fator 
apontado por Edésio Fernandes (2010, p. 56) que contribuiu para a reprodução de um processo urbanizatório excludente:

Foi a prevalência de uma ordem jurídica obsoleta e mesmo proibitiva quanto aos direitos de propriedade imobiliária que, ignorando a princípio da função social da propriedade que consta de todas as Constituições Federais desde 1934, seguiu afirmando o paradigma anacrônico do Código Civil de 1916, reforçando assim a tradição histórica de reconhecimento de direitos individuais de propriedade sem uma maior qualificação.

É neste contexto que se desenvolvem diversos movimentos sociais que reivindicavam melhorias nas condições da vida urbana. Dá passagem da década de 1970 para a década 1980, os movimento populares se transformaram deixando as reivindicações pontuais de lado e ampliaram suas pautas para questões mais abrangentes, se concentrando em torno de setores mais sensíveis do social, como direitos mínimos e básicos dos indivíduos enquanto cidadãos, bem como contra o regime ditatorial instalado (GOHN, 1991).

É neste contexto que as lutas sociais por mudanças no espaço urbano reacenderam no país, Edésio Fernandes (2010, p. 57) aponta que "um Movimento Nacional de Reforma Urbana emergiu neste período, envolvendo parte dos movimentos sociais existentes, sindicatos e organizações acadêmicas, e começou a ganhar destaque dentro do processo de redemocratização do país".

Em relação ao processo de enfrentamento que os movimentos sociais encabeçaram, em especial o Movimento pela Reforma Urbana, Raquel Rolnik (2012, p. 87) afirma que tanto a luta pelo direito à cidade, que na visão da autora tem como um dos componentes principais a direito à moradia, "emergiu como contraposição a um modelo de urbanização excludente e espoliativo, que ao longo de décadas de urbanização acelerada, absorveu em poucas e grandes cidades - sem jamais integrá-los - grandes contingentes de pobres migrantes de zonas rurais e pequenas cidades do país", essa mobilização culminou na inserção no texto constitucional de um capítulo direcionado à Política Urbana.

A inserção de um capítulo sore política urbana no texto constitucional de 1988, representou uma grande vitória para a sociedade brasileira, uma vez que esta disposição nunca antes havia existido nos textos constitucionais pátrios (FERNANDES, 2006). 
Além do ineditismo legislativo, das palavras de Edésio Fernandes (2006, p. 7) é possível perceber que o capítulo, composto por dois artigos representaram muito mais, eles "revolucionaram a ordem jurídica brasileira ao reconhecer que o Brasil já se encontrava plenamente urbanizado, e que as formas de organização socioeconômicas e político-territorial do país eram de outra ordem que não aquelas reconhecidas pelo Código Civil de 1916".

Muitos desses avanços se deram em função da mobilização social, mais de 100 mil organizações sociais e integrantes do Movimento Nacional pela Reforma Urbana, elaboraram uma Emenda Popular de Reforma Urbana que continha os seguintes princípios: autonomia do governo municipal, gestão democrática das cidades; direito social de moradia; direito à regularização de assentamentos informais consolidados; função social da propriedade urbana e combate à especulação imobiliária, e em certa medida, estes princípios podem ser identificados na Constituição, mesmo que sua inserção não tenha sido tão fácil (FERNANDES, 2010).

A promulgação da Constituição Federal de 1988, dispondo a respeito da política urbana, deu início a um processo de transformação da forma como a propriedade vinha sendo concebida no país. A concepção individualista, inspirada na concepção civilista de propriedade, foi substituída por uma concepção que tem como núcleo a função da propriedade (FERNANDES, 2006). E de acordo com Edésio Fernandes (2010, p. 59):

A Constituição Federal de 1988 deu um passo além, e adotou também o conceito das 'funções sociais da cidade', abrindo assim um amplo escopo jurídico - ainda pouco compreendido e aproveitado - para toda uma nova maneira de se pensar o processo de urbanização e a distribuição dos ônus e benefícios a ele inerentes.

O caput do artigo dispõe que a política de desenvolvimento urbano, executada pelo poder público municipal, conforme diretrizes gerais fixadas em lei, tem por objetivo ordenar o pleno desenvolvimento das funções sociais da cidade e garantir o bem-estar de seus habitantes. Deixando claro, a preocupação com a ordenação do desenvolvimento urbano com o objetivo de garantir as funções sociais da cidade.

Ao longo dos anos, outras iniciativas foram incorporadas as mudanças trazidas pela Constituição, cabe destacar entre essas iniciativas, a criação do Ministério das Cidades em 2003; as conferências Nacionais, estaduais e municipais das cidades; 
Conselho Nacional das Cidades; Programas federais urbanos, como a Programa de Aceleração do Crescimento (PAC) e o Programa Minha Casa Minha Vida (PMCMV) (FERNANDES, 2013).

A aprovação do Estatuto da Cidade se deu mais de dez anos depois da promulgação da Constituição sendo marcada por intensas discussões e negociações no Congresso Nacional (FERNANDES, 2006). A principal característica apontada pelos estudiosos em relação ao Estatuto é o de consolidação da competência jurídica municipal, bem como da ampliação da ação política do poder público municipal (FERNANDES, 2006).

Arlete Moysés Rodrigues (2004, p. 12) faz uma ponderação muito relevante em relação ao Estatuto da Cidade ao afirmar que ele "não resolve nem elimina os conflitos, mas os retira da sombra, mostrando que a sociedade é desigualmente constituída. Reconhece também, o predomínio da população urbana e a falta de acesso da maioria aos padrões de urbanidade vigentes". Ainda de acordo com a autora, o Estatuto tem seu mérito destacado, ao inovar a perspectiva em relação à cidade, ao olhar para a cidade real, ou seja, para as complexas relações de produção das e nas cidades.

Para sintetizar suas ponderações em relação ao Estatuto da Cidade e o que ele representa, Arlete Moysés Rodrigues (2004, p. 13) aponta que ele:

Reafirma a propriedade privada/individual, impõe alguns limites à especulação, induz o reconhecimento da cidade como produção coletiva, cria novos instrumentos jurídicos e participativos que permitem ao poder público tomar providências para que as propriedades cumpram sua função social em prol do bem coletivo, da segurança e do bem-estar dos cidadãos.

Apesar do Estatuto ter sido ovacionado quando da sua promulgação, Edésio Fernandes (2006, p. 7) destaca que "o Brasil tem ganhado prêmios internacionais pelo simples fato de ter aprovado o Estatuto da Cidade", e os desafios que ele enfrenta ainda são grandes, principalmente em relação à materialização da ordem jurídica instaurada pela Constituição e sedimentada pelo Estatuto da Cidade e por outras legislações correlatas (FERNANDES, 2006).

Para Edésio Fernandes (2013, p. 225), um dos principais desafios enfrentados pelo Estatuto da Cidade está no seu público alvo, ou seja, urbanistas, gestores, juristas e 
sociedade, esses atores devem compreender o real significado do Estatuto, principalmente no sentido de entendê-lo como a norma que:

Consolidou um novo paradigma jurídico sobre a questão da propriedade imobiliária, concebida não mais apenas em função do reconhecimento dos direitos individuais, mas também e sobretudo em função do reconhecimento das responsabilidades e obrigações sociais que resultam da condição de ser proprietário de um bem imóvel, bem como dos direitos coletivos e sociais sobre o solo urbano e seus recursos.

Essa responsabilização social atribuídas aos proprietários de bens imóveis, traduzida no princípio da função social da propriedade, pode ser considerada como o núcleo do direito à cidade. É o que depreende das palavras de Thiago Aparecido Trindade (2012, p. 140) quando afirma que "a institucionalização jurídica do direito à cidade somente se justifica na perspectiva da função social da propriedade, ou seja, este é o princípio que define o direito à cidade em termos legais". Sendo o princípio da função social nuclear para o direito à cidade, como já foi apontado, ele se desdobra em múltiplos direitos ou múltiplas dimensões que o compõem.

As diretrizes gerais citadas pelo texto constitucional foram fixadas pela Lei $\mathrm{n}^{\mathbf{o}}$ 10.257 de 2001, autodenominada Estatuto da Cidade, que de acordo com Ana Maria Furbino Bretas Barros, Celso Santos Carvalho e Daniel Todtmann Montandon (2010, p. 93) define as diretrizes para a elaboração das políticas públicas municipais urbanas "todas elas voltadas para garantir cidades justas, em que todos, pobres e ricos, desfrutem dos benefícios da urbanização". O Estatuto busca, disciplinar a elaboração da política urbana de modo que tanto o bônus quanto o ônus de desenvolvimento urbano seja distribuído de forma equitativa.

No artigo $2^{\circ}$, que disciplinou as diretrizes para a política urbana brasileira houve a disposição expressa do direito coletivo à cidade sustentável, que é compreendido como "o direito à terra urbana, à moradia, ao saneamento ambiental, à infraestrutura urbana, ao transporte e aos serviços públicos, ao trabalho e ao lazer, para as presentes e futuras gerações", que conjugado com as outras diretrizes disciplinadas nos incisos do referido artigo, demostram a multidimensionalidade do direito à cidade.

$\mathrm{Na}$ esfera jurídica, como é possível observar na definição de cidades sustentáveis, o direito à cidade não se constitui apenas como o direito ao acesso à cidade, mas traz dentro de si, o direito à terra urbana, por exemplo, que como afirmam 
Orlando Alves dos Santos Júnior e Cristiano Müller (2008, p. 9) é "o direito a participar na propriedade do território urbano, o uso socialmente justo e ambientalmente equilibrado do espaço e do solo urbano".

O direito à moradia, por sua vez, também guarda em si uma multiplicidade de direitos, não se tratando apenas de um local para morar. No âmbito internacional, o direito à moradia está previsto no art. 11 do Pacto Internacional dos Direitos Econômicos Sociais e Culturais. No âmbito interno, foi inicialmente previsto no texto Constitucional no art. $6^{\circ}$, capítulo dos Direito Sociais, e reafirmado no próprio Estatuto da Cidade como componente do Direito à Cidade Sustentável.

Para sedimentar uma interpretação oficial acerca do direito à moradia adequada, O Comitê dos Direitos Econômicos, Sociais e Culturais, elaborou o Comentário Geral $\mathrm{n}^{\mathrm{o}}$ 4. De acordo com o referido comentário, o direito à moradia adequada abrange a segurança jurídica da posse; a disponibilidade de serviços, materiais, facilidades e infraestrutura; custo acessível; habitabilidade; acessibilidade; localização e adequação cultural. De acordo com Edésio Fernandes e Betânia Alfonsin (2014, p. 19) "esse comentário foi de grande importância para superar uma visão reducionista do direito à moradia, que o restringia a direito a abrigo".

Outros elementos destacam-se no Estatuto da Cidade que se configuram como elementos que compõem o Direito à Cidade. É possível citar o inciso II do art. $2^{\circ}$ do estatuto, no qual prevê a gestão democrática da cidade, através de promoção da participação da população através de associações representativas, tanto na elaboração, quanto na execução e fiscalização de planos, programas e projetos de desenvolvimento urbano. Mecanismo este que abre espaço para que população participe ativamente na construção do espaço urbano.

No que diz respeito ao uso e desfrute igualitário das cidades e ao uso socialmente justo do solo urbano, o Estatuto da Cidade prevê, por exemplo, mecanismos jurídico urbanísticos que têm como objetivo estimular os proprietários a darem uma utilização adequada ao imóvel urbano que não esteja edificado, ou que no caso de edificação, não esteja sendo utilizado ou esteja sendo subutilizados. Para estes casos, o Estatuto da Cidade regulamento o parcelamento, edificação e utilização compulsórios. 
E como mecanismos de punição aos proprietários que mesmo diante do estabelecimento da obrigação do parcelamento, da edificação ou utilização, por parte do Poder Público Municipal, permanecerem sem dar uma destinação socialmente adequado ao imóvel urbano, o estatuto prevê a cobrança do IPTU progressivo no tempo, bem como a desapropriação do imóvel. A usucapião especial de imóvel urbano, destinada ao atendimento do Direto à Cidade à população de baixa renda.

Os dispositivos citados, constituem alguns exemplos dos diversos outros instrumentos presentes no Estatuto da Cidade que juntos, constituem um significativo avanço legislativo no que diz respeito à consolidação do Direito à Cidade no Brasil. Dessa forma, observa-se que, no que diz respeito ao ordenamento jurídico, o Brasil possui um sólido arcabouço legal no qual se fundamenta o Direito à Cidade nas suas mais diversas dimensões.

\section{CONSIDERAÇÕES FINAIS}

O Direito à Cidade a partir da sua perspectiva político-filosófica pode ser compreendido como um conceito essencialmente questionador da forma como as cidades são construídas nas sociedades capitalistas, nas quais a cidade enquanto mercadoria prevalece sobre os usos sociais e coletivos do espaço urbano. Neste sentido, o Direito à Cidade somente seria possível a partir do rompimento com a lógica capitalista e consequentemente com a lógica capitalista de produção do espaço urbano.

No entanto, a essa perspectiva político-filosófica, desenvolveu-se a perspectiva jurídica em relação ao Direito à Cidade. Inicialmente a temática das cidades surgiu no debate internacional vinculada a questão da sustentabilidade. Consolidando neste âmbito, a partir da década de 1990, o conceito de cidades sustentáveis. Paulatinamente a discussão passa da sustentabilidade urbana para a construção do denominado Direito à Cidade. No âmbito internacional, destacam-se a Carta Mundial pelo Direito à Cidade e a Nova Agenda Urbana.

Na Carta e Mundial pelo Direito à Cidade e na Nova Agenda Urbana é possível identificar uma definição de direito à cidade que amplia o conceito de cidade e agrega em torno de si diversas dimensões. Direito à Cidade configura-se como o direito a ter uma moradia digna, direito à participar da produção do espaço urbano, participar da 
propriedade urbana, direito ao acesso à serviços e à infraestrutura pública, à saúde, à educação, ao trabalho, ao lazer, à justa distribuição dos bônus e dos ônus do desenvolvimento.

No Brasil percebe-se que a questão urbana configura como uma das principais questões pautadas pelos movimentos sociais desde o processo de redemocratização iniciado a partir de 1980. As reivindicações sociais, através da mobilizações fizeram constar um capítulo inédito no texto constitucional a respeito da política urbana, regulamentado somente treze anos depois, através da Lei no 10.257 de 2001, o Estatuto da Cidade.

Analisando as disposições que compõem o Estatuto da Cidade, suas diretrizes gerais, os instrumentos jurídico-urbanísticos criados, é possível perceber uma influência clara das discussões desenvolvidas no contexto internacional. Apesar do Estatuto da Cidade ter sido promulgado antes da finalização do Carta pela Direito à Cidade, bem como da nova Agenda Urbana, é possível perceber que ele alcança, de forma significativa, as dimensões que compõem o Direito à Cidade previstas nestes documentos.

\section{REFERÊNCIAS BIBLIOGRÁFICAS}

ACSELRAD, Henri. Sentidos da sustentabilidade urbana. In: ACSELRAD, Henri (org.). A duração das cidades: sustentabilidade e risco nas políticas urbanas. Rio de Janeiro: DP\&A, 2001, p. 27-55.

BARROS, Ana Maria Furbino Bretas; CARVALHO, Celso Santos; MONTANDON, Daniel Todtmann. O Estatuto da Cidade comentado (Lei $n^{\circ} 10.257$ de 10 de julho de 2001). In: CARVALHO, Celso Santos; ROSSBACH, Ana Cláudia (orgs.). O Estatuto da Cidade: comentado. The City Statute of Brazil: a commentary. São Paulo: Ministério das Cidades: Aliança das Cidades, 2010.

FERNANDES, Edésio; ALFONSIN, Betânia. Direito à moradia - o que é, para quem serve, como é garantido e as disputas na construção doutrinária e jurisprudencial. In: FERNANDES, Edésio; ALFONSIN, Betânia (coords.). Direito à moradia adequada: O que é, par quem serve, como defender e efetivar. Belo Horizonte: Fórum, 2014.

FERNANDES, Edésio. Estatuto da Cidade, mais de 10 anos depois: razão de descrença, ou razão de otimismo. Revista UFMG. Belo Horizonte, vol. 20, n. 1, jan./jul., 2013, p. 212-233.

FERNANDES, Edésio. O Estatuto da Cidade e a ordem jurídico-urbanística. In: 
CARVALHO, Celso Santos; ROSSBACH, Ana Cláudia (orgs.). O Estatuto da Cidade: comentado. The City Statute of Brazil: a commentary. São Paulo: Ministério das Cidades: Aliança das Cidades, 2010.

FERNANDES, Edésio. Constructing the 'right to the cyti' in Brazil. Social \& Legal Studies, vol. 16, nº. 2, 2007, p. 201-219.

FERNANDES, Edésio. A nova ordem jurídico-urbanística no Brasil. In: FERNANDES, Edésio; ALFONSIN, Betânia (orgs.). Direito urbanístico: estudos brasileiros e internacionais. Belo Horizonte: Del Rey, 2006.

FERNANDES, Edésio. Do código civil ao estatuto da cidade: algumas notas sobre a trajetória do direito urbanístico no Brasil. In: FERNANDES, Edésio; ALFONSIN, Betânia. Evolução do direito urbanístico brasileiro. Belo Horizonte: PUC Minas Virtual, 2006.

GOHN, Maria da Glória. Movimentos sociais e luta pela moradia. São Paulo: Edições Loyola, 1991.

HARVEY, David. A liberdade da cidade. In: MARICATO, Ermínia [et al.]. Cidades rebeldes: passe livre e as manifestações que tomaram as ruas do Brasil. São Paulo: Boitempo: Carta Maior, 2013.

HARVEY, David. Cidades rebeldes: do direito à cidade à revolução urbana. Tradução Jeferson Camargo. São Paulo: Martins Fontes, 2014.

LEFEBVRE, Henri. O Direito à cidade. Tradução Rubens Eduardo Frias. São Paulo: Centauro, 2001.

MARICATO, Ermínia. Brasil, cidades: alternativas para a crise urbana. $7^{\mathrm{a}}$ ed. Petrópolis: Vozes, 2013.

OSÓRIO, Letícia Marques. Direito à Cidade como direito humano coletivo. In: FERNANDES, Edésio; ALFONSIN, Betânia (coords.). Direito urbanístico: estudos brasileiros e internacionais. Belo Horizonte: Del Rey, 2006.

RODRIGUES, Arlete Moysés. Estatuto da Cidade: função social da cidade e da propriedade. Alguns aspectos sobre população urbana e espaço. Cadernos Metrópole, n. $12,2^{\circ}$ sem., 2004, p. 9-25.

ROLNIK, Raquel. Dez anos do Estatuto da Cidade: das lutas pela reforma urbana às cidades da Copa do Mundo. In: RIBEIRO, Ana Clara T.; VAZ, Lilian V.; SILVA, Maria Lais P. (org.). Leituras da cidade. Rio de Janeiro: ANPUR; Letra Capital, 2012. P. 87-104.

SANTOS JUNIOR, Orlando Alves dos; MÜLLER, Cristiano (orgs.). Direito Humano à Cidade. Coleção Cartilhas de Direitos Humanos, vol. VI, $1^{\text {a }}$ ed., Curitiba: Plataforma Dhesca Brasil, 2008. 
SAULE JÚNIOR, Nelson. Direito à cidade: trilhas legais para o direito às cidades sustentáveis. São Paulo: Max Limonad, 1999.

SINGER, Paul. O uso do solo urbano na economia capitalista. In: MARICATO, Ermínia (org.). A produção capitalista da casa (e da cidade) no brasil industrial. São Paulo: AlfaÔmega, 1979.

TIETZMANN E SILVA, José Antônio. As perspectivas das cidades sustentáveis: entre a teoria e a prática. Revista de Direito Ambiental. ano 11, jul./set. 2006.

TRINDADE, Thiago Aparecido. Direito e cidadania: reflexões sobre o direito à cidade. Lua Nova. São Paulo, 87, 2012, p. 139-165.

UNIDAS, Naciones. Nueva Agenda Urbana- Declaración de Quito sobre Ciudades y Asentamientos Humanos Sostenibles para Todos. Equador, 2016. 